\title{
Special Care Dentistry
}

Disability is common. It will touch the lives of one in four of us. People with disabilities and complex additional needs should have equal access to oral health care services and equitable oral health outcomes. Currently this is not the case and, although people with disability (particularly those with learning disability or mental health problems) have similar patterns of oral disease to the general population, the evidence is that they have poorer oral health and poorer health outcomes from care.

Current health and social policy is directed towards reducing health inequalities through better co-ordinated activity that crosses traditional boundaries so that agencies work in partnership to improve quality of life and access to health services of vulnerable and disabled people.

The ethos of Special Care Dentistry (SCD) has always echoed this philosophy. SCD is defined by a diverse client-group with a range of disabilities and complex additional needs including people living at home, in long stay residential care and secure units, as well as homeless people. It is concerned with the improvement of oral health of individuals and groups in society who have a physical, sensory, intellectual, mental, medical, emotional or social impairment or disability (or, more often, a combination of a number of these factors) through this broad-based, cross-agency, partnership approach. The development of a Specialty in SCD would provide a better balance between need and provision, and between prevention and treatment, which is exactly what the Government is working towards in tackling health inequalities.

The debate about a Specialty started in the 1990s when the General Dental Council (GDC) and the Department of Health (DoH) sought to formalise and regulate the provision of Specialist care within the UK. A DoH review of existing Specialties and the need for future Additional Specialties recognised the case for a future Specialty in SCD. During this consultation period, the British Society for Disability and Oral Health developed standards for a Specialist training framework and the debate about specialisation in Community Dental Practice began.

Discussions continued over the need for a Specialty that would provide high quality care for people with a range of primary conditions with recognised special oral health care needs and management requirements; and for formalised training and professional development in this field. As a result, the Development Group for Community Dental Practice was established in 1995 under the aegis of the Faculty of Dental Surgery of the Royal College of
Surgeons (RCS) of England. This group published a report 'Moving Forward - Establishing the Specialty of Special Care Dentistry' that confirmed the need for further education and training, through a specialist framework, to improve and safeguard care for people with disabilities. Independently, and simultaneously, the Standing Committee on Postgraduate Medical and Dental Education acknowledged that there was "a strong case for formal education and training of dentists in the care of patients with special needs."

In 1999 the Dean of the Faculty of Dental Surgery of the RCS (England) established a Working Group in SCD to provide a broad-based, expert view to the Faculty of Dental Surgery later that year. The Group recommended the establishment of a Joint Advisory Committee for Special Care Dentistry (JACSCD). Consequently, in 2000, JACSCD was established as a free-standing committee to promote and oversee the introduction of training programmes, the development of curricula and training standards and formative assessment processes. Its documents 'A Case of Need - a proposal for a Specialty in Special Care Dentistry' and 'Training in Special Care Dentistry' were produced in 2003.

On 7 December 2005 the GDC approved, in principle, the establishment of a Specialty of SCD. Although there is still a long way to go to establish a specialist training pathway, the popping of champagne corks could be heard as special care dentists around the country celebrated. They celebrated the fact that this will lead to the establishment of a recognised and structured network of oral health care facilities for people with disability. They celebrated the fact that it will lead to formalised training that will attract young dentists and maintain a skilled workforce. They also celebrated a milestone on a long journey.

It has been said that all truth passes through three stages. In the first stage, it is ridiculed; in the second it is violently opposed; and in the third it is accepted as being self-evident. This process mirrors the journey of the establishment of a Specialty in SCD. It has been a long journey, which has not yet ended, nor have all the obstacles been overcome, but it is a wonderful end to the beginning!

Dr Janice Fiske MBE

Senior Lecturer and Consultant in Special Care Dentistry Chairperson of JACSCD

doi: $10.1038 /$ sj.bdj.4813217 